- 貝

\title{
Differences between National Cultures Matter - Case of Slovenian-Korean Working Environment
}

\author{
Matej Tušar ${ }^{1}$, Anja Žnidaršič ${ }^{2}$, Gozdana Miglič² \\ ${ }^{1}$ Kolektor Group, Idrija, Slovenia \\ matej.tusar@kolektor.com \\ ${ }^{2}$ University of Maribor, Faculty of Organizational Sciences, Kranj, Slovenia \\ anja.znidarsic@fov.uni-mb.si,gozdana.miglic@fov.uni-mb.si
}

\begin{abstract}
Aims: Global business today usually requires organizations to be present locally in countries where their customers are. To do this successfully, good cooperation with local people is needed. Therefore, this paper focuses on the integration of cultures in the business world. The insights from this study are expected to benefit Slovenian expatriates to foreign companies in South Korea, as well as national culture researchers. The main goals of this research include a comparison of Hofstede's IBM survey results with the researched working environment, and identifying the benefits of merging two national cultures for the working environment.

Methods: A questionnaire was distributed to purposive samples within the researched working environments and the collected data analysed used SPSS, where the hypotheses were tested using a chi-square test and t-test for independent samples.

Results: The results revealed significant differences between the two national cultures in the working environment, e.g.: fear of expressing disagreement towards superiors, commitment to work, preference of challenges, tendency to avoid conflicts and innovations - all differed according to nationality.

Conclusion: Working together with people from different cultures requires a certain amount of adaptation (learning about another culture, expecting situations that are not usual). If this adaptation is successful, then cooperation between the different cultures can also be successful, leading to a potential output that is even better than cooperation between people from the same culture.
\end{abstract}

Keywords: organizational behaviour, national culture, organizational culture, working environment, South Korea, Slovenia

\section{Introduction}

Globalization is now a popular term, as advancements in modern technology and travel have provided access to practically all countries and a heightened awareness of every race and ethnic affiliation. The following definition of globalization has been proposed by Al-Rodhan and Stoudmann (2006, p. 5): "Globalization is a process that encompasses the causes, course, and consequences of transnational and transcultural integration of human and non-human activities."

Every country is unique in its own way, it has its own national culture, values, habits, and way of life. The consequence of globalization is interaction between these various national cultures. Storti (2007) says that, in most cases, when in a new culture, people seek to adapt themselves, yet not all are successful. He continues that cultural adaptation is a phrase that refers to the process of 
learning a new culture and its behaviours and language in an effort to understand and empathise with the people of the culture and to live and interact successfully with them. Hofstede, Hofstede and Minkov (2010) emphasise cultural relativism - it calls for suspending judgement when dealing with groups or societies different from one's own and how we should think twice before applying the norms of one person, group, or society to another. Johns and Saks (2008) mention an example of how perception, attribution, and judgement of others impact one's position in an organization and how avoidance of premature judgement can prevent this. In real life, we believe we know the typical characteristics and through studies of different experts (e.g. Hofstede's IBM research, which was, according to Hofstede (2001) conducted around 1968 and 1972) even the habits and behaviour of nations, yet sometimes we also lean on stereotypes, and stereotypes are, according to Hofstede (2001), at best half-truths. Rather, it is actual international interaction that shows us how much we really know about others. A successful international relationship is in fact very fragile, and depends on how we handle even the smallest, seemingly unimportant details. The harshest consequence of mishandling details can even lead to war, which is actually surprisingly common. When we visit a foreign country without educating ourselves about its culture first, we can find ourselves constantly in conflict with the locals. "When two people from different cultures meet, they rely on their past experiences and judgment to decide which communication is appropriate. However, if the two have conflicting needs, it is important to focus on what initially seems to be inappropriate communication" (Merkin, 2015, para. 18).

Organizations exist in every culture, and these organizations vary from the family to huge business enterprises. How these organizations function is based on the national culture, yet to keep functioning well when expanding across a national border can be a challenge. According to Hofstede (ITAP International, n. d.), what is often overlooked or at least underestimated when two or more companies merge/integrate is how the underlying personal values of the employees impact on the perception of the corporate culture change efforts. Adaptation to processes and priorities is something a person can learn, and following the exemplar behaviour of leaders in an organization is something a person can be persuaded to do. However, a problem occurs if these priorities and the leadership traits go against the deeply held national cultural values of the employees, as then the corporate values (processes and practices) will be undermined. It has also been shown that what is appropriate in one national setting is wholly offensive in another, and what is rational in one national setting is wholly irrational in another. Corporate culture never trumps national culture. "It needs to be taken under consideration, that an attempt of integration of very remote and culturally different units into an effective unit is a great challenge" (Treven, 2001, p. 19). Treven (2001) also states that it is very important for managers in a global economy to understand and recognize the effect different cultures have on organizational behaviour, because national values, behaviour, tradition, customs, and ideology create recognition of organizational structure, culture, and dynamics. She also says that for organizations that face an outside environment, this environment is more complex, dynamic, and competitive than the local one, so, in order to perform successfully in it, they have to know other cultures and behaviour in their organizations.

This paper presents part of a wider research conducted in 2015. The purpose of the research was to explore Slovenian-Korean interactions. However, this paper focuses on intercultural integration in the business world, which may be valuable for expatriates working for foreign companies in South Korea, and for researchers of national cultures in the working environment. The two main goals of the research were: (i) to compare Hofstede's 1968 and 1972 IBM survey results (Hofstede, 2001) with our researched working environment, and (ii) to determine if merging the characteristics of two national cultures can be helpful within a working environment. The paper is organized in five sections: the introduction is followed by a literature review, the third section describes the methodology of the research, and the last two sections present the results and discussion with conclusions.

\section{Literature review}

The topic of national cultures and their impact on organizational culture is mainly studied within organizational behaviour. According to Robbins and Judge (2013), organizational behaviour is an applied behavioural science built on contributions from a number of behavioural disciplines, e. g. psychology and social psychology, sociology, and anthropology. Psychology's contributions have been mainly at the individual or micro level of analysis, while the other disciplines have contributed to our understanding of macro concepts, such as group processes and organization. Johns and Saks (2008) simplify organizational behaviour as the attitudes and behaviours of individuals and groups in an organization. Meanwhile, Treven (2001) writes that principles of organizational behaviour play an important role in assessing and increasing organizational effectiveness and that we can take this as a primary task for which all managers in organisations are responsible for.

Now add an international aspect to organizational behaviour: "Although all members in organizations are human beings, individuals working with different cultures and nationalities experience diverse difficulties that cannot be assumed as similar to those individuals working in a homogenous setting" (Dolan and Lingham, 2012, p. 19). But, 
what is culture exactly? According to Završnik and Miglič (2010), the word culture comes from the Latin word »colere" and means construction, fostering, and nursing. It means people acting based on traditions and general behaviour patterns, so culture is a summary of history, knowledge, experience, beliefs, comprehension, customs, valuations, time, and space valuations. Culture is unwritten rules followed by a certain group of people. According to Hofstede (2001), cultures are not king-size individuals but wholes, and their internal logic cannot be understood in the terms used for the personality dynamics of individuals. Hofstede, Hofstede and Minkov (2010) associate culture with mental software and such mental programs vary as much as the social environments in which they were acquired. They continue by marking culture as a collective phenomenon, because it is at least partly shared with people who live or lived within the same social environment where it was learned. Further, they explain that regional, ethnic, and religious cultures account for differences within countries, while ethnic and religious groups are often not limited to country borders.

Hofstede, Hofstede and Minkov (2010) also define four dimensions of national cultures: power distance, collectivism versus individualism, femininity versus masculinity, and uncertainty avoidance. The power distance represents the extent of the acceptance of unequally distributed power, where countries with a high power distance have a pronounced superior authority. In such countries, management by objectives (MBO) does not work, simply because it presupposes some kind of negotiation between superiors and subordinates. Meanwhile, in low power distance countries, there is a certain equality between superiors and subordinates, thus the hierarchical system is flat and roles are sometimes reversed. Collectivism versus individualism relates to the prevalence of the interests of groups or individuals. "Individualism pertains to societies in which the ties between individuals are loose: everyone is expected to look after him- or herself and his or her immediate family. Collectivism as its opposite pertains to societies in which people from birth onward are integrated into strong, cohesive in-groups, which throughout people's lifetime continue to protect them in exchange for unquestioning loyalty (Hofstede, Hofstede and Minkov, 2010, p. 92)." Femininity versus masculinity means whether genders have clearly distinct emotional roles or not. Along with masculinity and femininity, Hofstede, Hofstede and Minkov (2010) also describe two other characteristics, assertiveness and modesty. Masculinity and femininity is relative, males can act feminine, as well as females can act masculine, however the general trend is that males should be more occupied with achievements away from home (traditionally hunting and fighting), while females are supposed to take care of the home and family. Finally, uncertainty avoidance is whether society tends to avoid everything that is different or is accepting it. According to Hofstede, Hofstede and
Minkov (2010), the term "uncertainty avoidance" was provided by Mr. James G. March. The researchers also state that ways of handling uncertainty are part of any human institution in any country. They add that all human beings have to face the fact that what will happen tomorrow is unknown: the future is uncertain, but we have to live with it anyway. Additionally, they say that uncertainty is a subjective experience, a feeling. Uncertainty avoidance can also be explained by an example of two different situations most of us would feel uncomfortable jumping off a bridge with a bungee rope, despite knowing the rope will hold us, whereas we would have no issue riding a mountain bike through the woods, even though the latter situation is more likely to lead to serious injury. Hofstede, Hofstede and Minkov (2010) say a dimension is an aspect of culture that can be measured relative to other cultures. However, organizational cultures are, according to Hofstede, Hofstede and Minkov (2010, p. 47), a phenomenon by themselves, different from national cultures in many respects. They say an organization is a different social system from a nation as the members usually did not grow up in it, but had a certain influence on their decision to join it, are involved in it only during working hours, and will one day leave it. Plus, a further comment was made that research on national cultures and their dimensions proved to be only partly useful for understanding organizational cultures.

According to the Hofstede Centre (2014a), the cultural characteristics of a Slovenian are:

- rather satisfied with a strong hierarchical society, recognizes advantage to their superiors and elders, and likes to see their superiors as more important and outstanding compared to their neighbours' superiors;

- integrated into a strong group that takes care of them and they strongly depend on, does not appreciate new challenges, personal time and freedom, but gives absolute advantage to perfecting of existing knowledge and to good working environment conditions;

- prone to feminine values - cooperation, harmony, security;

- has a great desire for an environment that is regulated with rules, resists innovations, is punctual, always busy and motivated to work hard;

- not particularly focused on the future, nor past or present time;

- not particularly spoiled nor retained.

Maybe these characteristics do not seem right, because some conclusions are totally opposite from the actual situation in Slovenia. However, some additional explanations are needed, especially for individualism/collectivism, where Slovenia scores more as a collectivist country, despite considering ourselves as an individualistic country. Treven (2001) characterizes Slovenians as individualists, while Hofstede, Hofstede and Minkov (2010) found in their summary of Minkov's research from 2007 that Slo- 
venia is somewhat special. Minkov added 2 poles, exclusionism and universalism, where Hofstede, Hofstede and Minkov (2010) defined exclusionism as a cultural tendency of treating people based on their connections with the group and reservations of favours for groups with which one identifies, and excluding all outsiders. Universalism on the other hand is the opposite tendency: to treat people based on who they are as individuals, not which group they are affiliated to. Within these poles Hofstede, Hofstede and Minkov (2010) put Slovenia among universalists. This is contrary to the previously defined character assumptions, and means Slovenians are actually much more open to outside people, as expected. When it comes to attitude towards work, we found from Slovenia partner (n. d.) that Slovenians are prone to separating their personal and business life, which consequently leads to more time available to spend with their families. On the Slovenian business portal and their Centre for international cooperation and development (2013), data identifies Slovenia as an »innovation follower« with innovations averaging above or close to the EU average and constantly growing. This fact alone is in complete contradiction to the general statement above for countries with a high uncertainty index, where resisting innovation is stated as one of the cultural characteristics for a Slovenian.

According to the Hofstede Centre (2014b), the cultural characteristics of a South Korean are:

- rather satisfied with a strong hierarchical society, recognizes advantage to their superiors and elders, and likes to see their superiors as more important and outstanding than their neighbours' superiors;

- integrated into a strong group that takes care of them and they strongly depend on, does not appreciate new challenges, personal time and freedom, but gives absolute advantage to perfecting existing knowledge and to good working environment conditions;

- $\quad$ prone to feminine values - cooperation, harmony, security;

- $\quad$ has a great desire for an environment that is regulated with rules, resists innovations, is punctual, always busy and motivated to work hard;

- totally dedicated to working for the future;

- $\quad$ retained and pessimistic.

There is a significant influence of Confucianism, which has, according to Coyner and Jang (2010), despite the fact that it originates from China, made its mark in Korea more than anywhere else, and so we can find reasons for all Korean values in Confucianism. As Coyner and Jang (2010) presented, the code and rules of Confucianism determine the loyalties, obligations, and responsibilities between the ruler and the subject, parent and child, young and old, and between friends and the rest. Coyner and Jang (2010) say that in South Korea, hard work and dedication to an organ- ization is regarded as a virtue. Anyone not in conformity with this value system is not accepted, sometimes even by their wife. Essentially, a wife finds it difficult to understand when her husband comes home sooner than her neighbour's husband, as this implies that the neighbour's husband has more important business activities than her husband. She wants to boast of the importance of her husband, even if it means working late hours. When it comes to rules, Kim Hoo-ran (2014) explains that there are many rules in Korea, yet people disregard them, which often has fatal consequences. This is attributed to the "ppalli ppalli" or "hurry hurry" culture, which is a by-product of the era which saw economic development as the overarching goal. In such a culture, decades were spent circumventing laws for the sake of reaching goals, thereby becoming insensitive to potential danger.

\section{Methodology}

"To work effectively with people from different cultures, you need to understand how their culture, geography, and religion have shaped them and how to adapt your management style to their differences" (Robbins and Judge, 2013, p. 17). The current research was conducted in 2015 using an anonymous survey within working environments. We studied whether in a mixed Slovenian-Korean working environment the indices of the researched dimensions on national culture for both nations remained in line with the results of Hofstede's IBM 1968 and 1972 surveys (Hofstede, 2001). As a result, people interested in a mixed working environment can have a good starting point to choose the right approach for coordinating these two cultures. Kolektor has existed for more than 50 years (Kolektor, n. d.), during which time it developed into a global company with its headquarters in Slovenia and companies in Europe, America, and Asia. The product portfolio ranges from components and systems for the automotive industry to energetics and industrial technologies. Treven (2001) says that managers in such companies must know the culture and other economics, social, and technological characteristics of the country in which production is set. This claim gave us the foundation for conducting research within Kolektor, as till now no such specific research has been done.

Kolektor in Slovenia consists of several companies scattered across the country, with a total of 2244 employees at the end of June 2015. Meanwhile, the Kolektor Sinyung Company in South Korea employed a total of 119 Koreans and 3 Slovenians at the end of June 2015. The origins of the Korean company go back to 1978, when it was started as a joint venture of Korean and Japanese investors with the intention of producing commutators. In 2000, the company was acquired by Kolektor, the revenues have since multiplied more than five times. The product portfolio consists entirely of components for the automotive industry. 
The aim of this study was to answer the following research questions:

RQ1: Are the working habits between the two cultures within the working environment different?

RQ2: Can the characteristics of the two different cultures be merged in a positive way?

More precisely, according to the research aims, several research hypotheses were investigated within each cultural dimension:

Power distance:

RH1: The expectations of the employees as regards their manager are related to the nationality of the employee.

RH2: The fear of expressing disagreement to a superior differs according to the nationality of the employee and manager.

Individualism/collectivism:

RH3: On average, Korean employees have a higher work commitment than Slovenian employees.

RH4: The approach to work is related to nationality.

Masculinity/femininity:

RH5: Avoiding conflict situations is related to nationality. Uncertainty avoidance:

RH6: Uncertainty avoidance is related to nationality.

\section{Population and sample}

As emphasized in the article title, the population was strictly limited to employees of the Kolektor Company in two locations, Korea and Slovenia, since we investigated the aspect of uncertainty avoidance between Slovenian and Korean cultures. A purposive sample was used, where the criterion for inviting employees to participate in the research was previous experience with the other culture (i.e. Slovenian or Korean) within the working environment.

\section{Development of instrument and data sources}

The questionnaire was based on Hofstede's questionnaire (Hofstede, 2001, p. 467 - 474), from where the following questions were adopted, some with exact wording, while others with some modifications. The socio-demographic characteristics included: marital status, length of employment by current company, estimated period of future employment for the company, educational status, and age. The questionnaire also included preferences and actual type of managers/superiors. In addition to the listed adopted questions, the following socio-demographic characteristics were also included: gender and position in the company. Plus, questions on fear of disagreement with a manager, reprimand effectiveness, preferred way of solving assignments and problems, acceptance of late working hours and breaking holidays due to work reasons, preferred renewal of old or build new machines, preferred type of ideas, im- portance of profit or growth, and requested holidays were specifically created for this research. Respondents were also asked to describe their experience in the other location (for Koreans this was Slovenia and vice versa). The questionnaire was prepared as an instrument for broader research, therefore, this study only deals with the results related to the dimensions covering nationality. The questionnaire was anonymous and no benefits were given to respondents who completed it.

\section{Data collection procedures}

In Slovenia, an online version of the questionnaire was distributed in Slovenian language, while in Korea, the questionnaires were handed out personally in a printed form in Korean language. The questionnaire was initially written in Slovenian, and then translated into English and finally into Korean with the help of a Korean manager. The questionnaires completed in Korean were translated into English by the same Korean manager.

The research sample consisted of two groups according to the location, but not limited to nationality (there is a possibility for a foreign respondent within the location group). The actual sample sizes were 71 respondents in Korea (representing $60 \%$ of the total employees in Korea) and 54 respondents in Slovenia (representing 2.4\% of the total employees in Slovenia). Altogether, the analyses included 125 completed questionnaires. The analyses of the gathered data were performed using SPSS (Statistical Package for Social Sciences), where different statistical methods were used: chi-square test and t-test for independent samples.

\section{Results}

The participant profile is presented first, followed by the results of the six research hypotheses within the four dimensions of culture.

\section{Participant profile}

The participant profile is presented based on the general demographic characteristics. Among the 125 questionnaire respondents, 93 were men (56 of whom were Korean) and 32 were women (12 of whom were Korean). 29 Slovenians and 41 Koreans were married and the majority (49) were aged $31-40$ years (40 were aged $41-50$ years, 28 were younger than 31 years, and 8 were aged 51 years or over). Most of the participants were also well educated: 5 had graduate degrees - Master's or Ph.D. (4 Slovenians and 1 Korean), 62 had undergraduate degrees (29 Slovenians and 33 Koreans), 45 had high school diplomas (12 Slovenians and 33 Koreans), and only 13 had completed secondary school (12 Slovenians and 1 Korean). However, most participants (50) worked as operators or technologists in production (11 Slovenians and 39 Koreans), 44 worked as 
engineers or administrative workers (24 Slovenians and 20 Koreans), 21 worked as managers or team leaders (12 Slovenians and 9 Koreans), and 10 worked in management (all Slovenians).

\section{Analyses of research hypotheses}

\subsubsection{Power distance}

For the first research hypothesis, we investigated whether the expectations of the employees about their manager were related to the nationality of the employee. The expectations of the employees about their manager were measured using a description of four types of manager according to Hofstede's research (2010). The respondents were asked to select one of the four manager types. The descriptions are shown in Table 1, along with a contingency table of the preferred manager type according to the nationality of the employee.

The hypothesis was tested using a chi-square test. As shown, that Slovenian respondents preferred manager 3 $(63 \%)$, and least preferred manager 1 (2\%). Meanwhile, the Korean respondents preferred manager 2 (44\%), followed by manager $4(27 \%)$, and only then manager 3 $(18 \%)$. Interestingly, in contrast to the Slovenian respondents, 8 Koreans $(12 \%)$ preferred to work with manager 1 .

Since the expected count was lower than 5 in two fields of the contingency table, Fischer's exact test was applied. The p-value was $0.000<0.05$, meaning that a null hypoth- esis, where the variables are not related, can be rejected at a 5\% significance level. As a result, the first research hypothesis was confirmed, the manager type preference was found to be related to the nationality of the employee.

The second research hypothesis (RH2) »Fear of expressing disagreement toward a superiors differs according to the nationality of the employee and manager« was divided into 2 parts:

$\mathrm{H} 2 \mathrm{a}$ : Average fear of expressing disagreement toward a superior differs according to nationality of employee.

$\mathrm{H} 2 \mathrm{~b}$ : Average fear of expressing disagreement toward a superior differs according to nationality of manager.

Both hypotheses were tested using a t-test for independent samples. The question about fear of expressing disagreement towards superiors was answered on a 5-point scale of frequency: 1 - very often, 2 - often, 3 - sometimes, 4 - rarely, and 5 - never. The average response for the Korean respondents was »rarely« (4.01, $s=1.029)$, whereas the Slovenian respondents showed more fear of expressing disagreement to a superior as the average response was classified as »sometimes« $(3.42, s=1.034)$.

First, the results of hypothesis $\mathrm{H} 2 \mathrm{a}$ are presented. Since the p-value for the Levene test of variance equality was $0.347>0.05$, this means that our null hypothesis of equality of variance could not be rejected at a $5 \%$ significance level. The t-test p-value was $0.002<0.005$, which means that the null hypothesis abouth the equality of the average frequency of fear could be rejected at a $5 \%$ significance level (Table 2). Therefore, the average fear of expressing

Table 1: Preferred manager type according to nationality of employee

\begin{tabular}{|c|c|c|c|}
\hline & & \multicolumn{2}{|c|}{ Nationality of employee } \\
\hline & & Slovenian & Korean \\
\hline \multirow{3}{*}{$\begin{array}{l}\text { Manager 1: Usually makes decisions promptly and } \\
\text { communicates them to subordinates clearly and firmly. } \\
\text { Expects subordinates to carry out the decisions loyally and } \\
\text { without raising difficulties. }\end{array}$} & Count & 1 & 8 \\
\hline & Expected Count & 4.1 & 4.9 \\
\hline & $\%$ within preferred manager type & $11.10 \%$ & $88.90 \%$ \\
\hline \multirow{3}{*}{$\begin{array}{l}\text { Manager 2: Usually makes decisions promptly, but, befo- } \\
\text { re going ahead, tries to explain them fully to subordinates. } \\
\text { Gives reasons for the decisions and answers whatever } \\
\text { questions subordinates may have. }\end{array}$} & Count & 12 & 30 \\
\hline & Expected Count & 19 & 23 \\
\hline & $\%$ within preferred manager type & $28.60 \%$ & $71.40 \%$ \\
\hline \multirow{3}{*}{$\begin{array}{l}\text { Manager 3: Usually consults with subordinates before } \\
\text { reaching a decison. Listens to advice, considers it, and } \\
\text { then announces the decision. Expects all to work loyally } \\
\text { to implement decision whether or not it is in accordance } \\
\text { with the advice given. }\end{array}$} & Count & 35 & 12 \\
\hline & Expected Count & 21.2 & 25.8 \\
\hline & $\%$ within preferred manager type & $74.50 \%$ & $25.50 \%$ \\
\hline \multirow{3}{*}{$\begin{array}{l}\text { Manager 4: Usually calls meeting of subordinates when } \\
\text { there is an important decision to be made. Puts the prob- } \\
\text { lem before the group and invites discussion. Accepts the } \\
\text { majority viewpoint as the decision. }\end{array}$} & Count & 8 & 18 \\
\hline & Expected Count & 11.7 & 14.3 \\
\hline & $\%$ within preferred manager type & $30.80 \%$ & $69.20 \%$ \\
\hline
\end{tabular}


Table 2: Descriptive statistics and results of corresponding t-tests for frequency of fear of expressing disagreement toward a superior according to nationality of employee and superior, respectively

\begin{tabular}{|c|c|c|c|c|c|c|c|c|c|c|}
\hline \multirow{2}{*}{ Test of hypothesis } & \multirow{2}{*}{ Nationality } & \multicolumn{4}{|c|}{ Descriptive statistics } & \multicolumn{2}{|c|}{ Levene's Test } & \multicolumn{3}{|c|}{$\begin{array}{c}\text { t-test for Equality of } \\
\text { Means }\end{array}$} \\
\hline & & $\mathbf{N}$ & Mean & $\begin{array}{l}\text { Std. De- } \\
\text { viation }\end{array}$ & $\begin{array}{l}\text { Std. Error } \\
\text { Mean }\end{array}$ & $\mathbf{F}$ & Sig. & $\mathbf{t}$ & Df & $\begin{array}{c}\text { Sig. } \\
\text { (2-tailed) }\end{array}$ \\
\hline \multirow{2}{*}{$\begin{array}{l}\text { H2a: Nationality of } \\
\text { employee }\end{array}$} & Slovenian & 57 & 3.42 & 1.034 & 0.137 & \multirow{2}{*}{0.891} & \multirow{2}{*}{0.347} & \multirow{2}{*}{-3.205} & \multirow{2}{*}{123} & \multirow{2}{*}{0.002} \\
\hline & Korean & 68 & 4.01 & 1.029 & 0.125 & & & & & \\
\hline \multirow{2}{*}{$\begin{array}{l}\text { H2b: Nationality of } \\
\text { superior }\end{array}$} & Slovenian & 58 & 3.41 & 1.027 & 0.135 & \multirow{2}{*}{0.766} & \multirow{2}{*}{0.383} & \multirow{2}{*}{-3.341} & \multirow{2}{*}{123} & \multirow{2}{*}{0.001} \\
\hline & Korean & 67 & 4.03 & 1.029 & 0.126 & & & & & \\
\hline
\end{tabular}

disagreement toward a superior was different according to the nationality of the employee at a $5 \%$ significance level.

Second, the results of hypothesis $\mathrm{H} 2 \mathrm{~b}$ are as follows. The respondents with a Slovenian manager showed a higher frequency of fear towards expressing disagreement (3.41) than the respondents with a Korean manager (4.03).

Based on the p-value from Levene's test $0.383>0.05$, the null hypothesis of equality of variance could not be rejected at a $5 \%$ significance level. The t-test $\mathrm{p}$-value was $0.001<0.05$, which means that the null hypothesis about the average equality of the frequency of fear towards expressing disagreement could be rejected at a $5 \%$ significance level. Thus, the frequency of fear of expressing disagreement towards superiors was found to differ according to the nationality of the manager. Therefore, the second research hypothesis that "Fear of expressing disagreement towards superiors differs according to the nationality of the employee and manager" was confirmed.

\subsubsection{Individualism/Collectivism}

The two hypotheses, RH3 and RH4, are related to the dimension of individualism and collectivism.

The third research hypothesis (RH3) assumes that work commitment is related to the nationality of the employee. Commitment to work was measured using two variables, thus dividing the hypothesis into:

H3a: Acceptability of overtime work is related to nationality of employee

H3b: Acceptabiltiy of vacation interruption due to an important projectis related to nationality of employee

The respondents evaluated if two situations seemed, and to what extent, acceptable to them. Both acceptability of overtime work as well as acceptability of a vacation interruption due to an important project were evaluated on a 5-point acceptability scale ranging from 1 - 'totally acceptable, the company needs me', 2 - 'difficult, but acceptable since the company needs me', 3 - 'not acceptable, but also not unacceptable', 4 - 'unacceptable, but in an urgent case I am prepared to make an exception', and 5 - 'totally unacceptable'. The hypothesis was tested using an independent samples t-test.

The results showed:

- in the case of overtime acceptability, both Slovenians and Koreans answered on average almost the same ( 1.86 for Slovenian and 1.84 for Korean respondents).

- in the case of acceptability of vacation interruption due to an important project, the Slovenian respondents had an average of 2.67 , while the Korean respondents evaluated the statement with an average equal to 2.31 , which means that, on average, the respondents answered between »difficult, but acceptable since the company needs me « and »not acceptable, but also not unacceptable«.

The results of the t-test for statistical hypotheses H3a and $\mathrm{H} 3 \mathrm{~b}$ are presented below.

- Acceptability of overtime work. In this case, Levene's test p-value was $0.201>0.05$, so we cannot reject our assumption about the equality of variances at a $5 \%$ significance level. The one-sided t-test $\mathrm{p}$-value was equal to $0.448(0.896 / 2>0.05)$, meaning that the null hypothesis about the average acceptability of overtime work between Korean and Slovenian employees could not be rejected at a $5 \%$ significance level.

- Acceptability of vacation interruption due to an important project. Levene's test p-value was $0.016<$ 0.05 , therefore the null hypothesis about the equality of variance could be rejected at a $5 \%$ significance level. The one-sided t-test p-value was $0.045(0.089 / 2<$ 0.05 ), therefore the null hypothesis about the average acceptability of vacation interruption due to an important project could be rejected at a 5\% significance level. On average, the Korean employees found a vacation interruption due to an important project more acceptable than the Slovenian employees.

Therefore, our third research hypothesis was partially confirmed; Koreans are more committed to work when it comes to vacation interruption, yet in the case of overtime 
work, there were no statistically significant differences at a $5 \%$ significance level.

The fourth research hypothesis assumes that the approach to work is related to nationality and was split into two parts:

RH4a: Way of resolving tasks is related to nationality of employee.

RH4b: Preferred kind of work is related to nationality of employee.

To test the above hypotheses, we used chi-square tests and the results regarding the way of resolving tasks were as follows. Among the Slovenian respondents, $44 \%$ preferred solving tasks individually, while $56 \%$ preferred team work. Among the Korean respondents, the situation was quite similar with a ratio of $43: 57 \%$ in favour of solving tasks individually.

The chi-square $\mathrm{p}$-value was equal $0.892>0.05$, indicating that our null hypothesis that the preferred way of task solving and nationality are not related could not be rejected at a 5\% significance level. This leads to the conclusion that the way of resolving tasks was not related to the nationality of the employee. However, when we compared the preferred kind of work and the employee's nationality, we found that the Slovenian respondents mostly (91\%) preferred work that is full of challenges, while among the Korean respondents, only $46 \%$ preferred this type of work.

The chi-square test p-value for RH4b was equal to $0.000<0.05$, meaning that the null hypothesis, that the preferred kind of work and nationality are not related, could be rejected at a 5\% significance level.

Therefore, based on the test results, RH4 was only partially confirmed - we found a clear association between the employee's nationality and the preferred kind of work (whether challenges are preferred or not), yet no significant difference associating nationality and the way of resolving tasks.

\subsubsection{Masculinity/Femininity}

To test the fifth research hypothesis, that avoiding conflict situations is related to nationality, a chi-square test was used.

The method of problem solving was measured through options: whether ideal or compromise solutions were preferred. It was found that $37 \%$ of the Slovenian respondents preferred an ideal solution, while $63 \%$ preferred a compromise. Meanwhile, for the Korean respondents, the percentage in favour of an ideal solution was much lower, only $15 \%$.

Based on the p-value of the chi-square test, which was $0.004<0.05$, our null hypothesis, that there is no relationship between the method of problem solving and nationality, could be rejected at a 5\% significance level. Thus, we confirmed our assumption that Koreans tend to prefer compromise solutions.

Therefore, based on the above results, the fifth research hypothesis »Avoiding conflict situations is linked to nationality« was fully confirmed.

\subsubsection{Uncertainty avoidance}

For the sixth research hypothesis, that uncertainty avoidance is related to nationality, this was measured using two concepts: rebuilding/changing machines and type of ideas used. The corresponding hypothesis were as follows:

RH6a: Preferred way of rebuilding/changing machines is related to nationality of employee.

RH6b: Preferred type of ideas used is related to nationality of employee.

The preferred way of rebuilding/changing machines was measured based on the respondents' opinion of what type of new machine they preferred; a totally new machine (which is cheaper, with better productivity, yet untested and with a questionable reliability) or an already tested design (not better in any way except guaranteed reliability).

For the preferred type of ideas used, two possibilities were also given, a new idea (with big potential, yet untested, so it could fail totally in practice) or a tested idea (which would mean higher costs, but an already proven success rate).

The results showed that, among the Slovenian respondents, $58 \%$ preferred to use a totally new machine, while $42 \%$ preferred to use a tested design. For the Korean respondents, the situation was reversed - fewer Koreans favoured using a new machine $(22 \%)$, while more preferred a tested design (78\%).

The chi-square test p-value for RH6a was $0.000<0.05$, indicating that the null hypothesis, that there is no relationship between the preferred way of rebuilding/changing machines and the nationality of the employees, could be rejected at a 5\% significance level. We also confirmed that Koreans prefer reliable and tested machines or systems.

As regards the preferred type of ideas used, the results showed that the Slovenian respondents were quite balanced, yet still more in favour of tested ideas (ratio 47 : $53 \%$ ), whereas the Korean respondents showed a much clearer tendency to use tested ideas (74\%).

The chi-square test p-value at RH6b was $0.015<0.05$, therefore our null hypothesis, that there is no relationship between the preferred type of ideas used and the nationality of the employees, could be rejected at a $5 \%$ significance level. Plus, this confirmed that Koreans prefer reliable and tested ideas. Thus, the sixth research hypothesis »Uncertainty avoidance is related to nationality« was fully confirmed. 


\section{Discussion}

This research addressed the topic of intercultural differences according to Hofstede's research, yet in this case translated to the specific working environment of Kolektor Sinyung. The main focus was comparing the dimensions of culture with the nationalities involved within this working environment - Korean and Slovenian. The goal was to provide as much information to the responsible director, as well as to any interested parties where such research of two cultures in a working environment could be useful.

The current results confirmed our assumptions that, for all the dimensions of culture, a relationship existed between certain variables (expectations of employees about their manager, fear of expressing disagreement towards superiors, work commitment, approach towards work, avoiding conflict situations, uncertainty avoidance) and nationality. The only exceptions were overtime work and the way of resolving tasks, both of which are part of the individualists/collectivists dimension, however, we still achieved partial confirmation. Thus, the differences between cultures were identified. Facts:

- Korean employees prefer more authoritative managers, yet seem to have less fear of expressing their mind to their managers than Slovenian employees;

- Koreans are more committed to work;

- Koreans do not like to create conflicts and thus prefer compromise where there is no winner;

- Koreans are reluctant to provide innovations or put innovations to use. However, Slovenians are much more open to using innovations in practice, yet less so in providing them.

Merging these cultural characteristics could, with the right approach, lead to a very successful business model. In particular, such potential can be seen in the following scenarios:

- mother companies from one culture trusting important and time-sensitive projects to their Korean colleagues, since Koreans are more likely to commit to work even during their free time;

- one culture (Slovenia) being more positive towards implementing new ideas, the other (South Korea) could complement it by being forced to study it and run it to perfection. This is supported also by Hofstede, Hofstede and Minkov (2010), who say that countries from both ends of the uncertainty avoidance index scale could supplement each other perfectly one providing ideas, the other implementing it.

The above conclusions are supported by our personal observations when working at Kolektor Sinyung where we noticed identical behaviour as described in the findings of The Hofstede Centre (2014). The working time alone is already a factor, as in Korea, one work shift normally lasts
12 hours (the legal maximum work week is 68 hours). In Slovenia the legal maximum is 48 hours. While the Korean government has been trying to reduce the maximum work week, the labour unions were strongly against it, which is opposite to the trend in Slovenia. The same goes for the upper age limit for working, which Koreans are continuously fighting to increase, while Slovenians are tyring to decrease.

Supportive of theory and the current results is another situation example which we personally observed. It happened at the beginning of 2011, soon after arriving in Korea. We entered the garage of our apartment block at around $18.30 \mathrm{~h}$ and saw a car with engine still runnin and a man sleeping inside. From the reports of other people, this was not a case of drunkenness, but rather connected to the example mentioned by Coyner and Jang earlier in our article.

As a final thought, let's see how Hofstede (2001) commented on a popular business slogan $»$ Think globally, act locally." According to Hofstede, this phrase is naiive and arrogant - no one can actually think globally, but we all think according to our local software. He continues that intercultural encounters are about recognizing that we think differently but are resolving our common problems anyway. His conclusion is a proposed slogan »Think locally, act globally«.

Potential limitations within this research: (i) unusually high number of university graduates among Korean participants, especially given the fact that most are working in production where we would normally expect workers with a lower grade of education. It could be argued it has to do with either a misunderstanding of the intended education level due to different school systems between the countries or the participants - despite the research being anonymous - feeling undervalued if they answered truthfully. (ii) The researched working environment has already existed many years, and was a mixture of Slovenian and Korean culture from the very beginning. This could mean that the workers in this environment have already adapted to some extent to each other over the years. Therefore, more significant differences would be evident if a new working environment were created (with totally new employees).

For potential future replications, a mixed cultural environment with no previous experience of the other cultures would be recommended.

\section{Literature}

Al-Rodhan, N.R.F., \& Stoudmann, G. (2006), Definitions of Globalization: A comprehensive Overview and a Proposed Definition, Geneva: Centre for Security Policy.

Coyner, T. L., \& Jang S. H. (2010). Doing Business in Korea: An Expanded Guide. Seoul: Seoul Selection.

Dolan, S., \& Lingham, T. (2012). Introduction to Interna- 
tional Organizational Behaviour. Logan: BookEducator.

Hofstede, G. (2001). Cultures consequences: Comparing values, behaviors, institutions, and organizations across nations ( $2^{\text {nd }}$ ed.). California: Sage Publications.

Hofstede, G, Hofstede, GJ, \& Minkov, M (2010). Cultures and organizations: software of the mind: intercultural cooperation and its importance for survival ( $3^{\text {rd }}$ ed.). (n. p.): McGraw-Hill.

ITAP International (n. d.), Integrating Corporate Practices and National Cultural Values. Retrieved March 30, 2016, from: http://www.itapintl.com/index.php/aboutus/latest-news/57-organizational-culture-and-nationalculture-what-s-the-difference-and-why-does-it-matter

Johns, G., \& Saks, A. M. (2008). Organizational Behaviour: Understanding and Managing Life at Work ( $7^{\text {th }}$ ed.). b.k.: Pearson Canada Inc.

Kim Hoo-ran (2014). Culture closely tied to Korea's vulnerability to disasters. Retrieved May 24, 2014, from http://www.koreaherald.com/view. php?ud $=20140513001280$

Koncern Kolektor (n. d.). About Kolektor. Retrieved May 15, 2014, from http://www.kolektor.com/en/about-thegroup

Merkin, R. (2015, November), `The Relationship between Individualism / Collectivism: Consultation and Harmony Needs'. Journal of Intercultural Communication. 39. Retrieved 10.01.2016, from http://immi.se/ intercultural $/ \mathrm{nr} 39 /$ merkin.html

Robbins, S. P., \& Judge, T. A. (2013). Organizational Behaviour ( $15^{\text {th }}$ ed.). New Jersey: Pearson Education Inc.

Slovenian Business Portal (2016, February). Doing Business in Slovenia. Retrieved March 1, 2016, from http:// poslovniportal.si/Doing Business Slovenia.php

Slovenia partner (n. d.). If you travel to Slovenia for business or pleasure. Retrieved March 3, 2016, from http:// www.sloveniapartner.eu/business-environment/business-visit/

Storti, C. (2007). The Art of Crossing Cultures ( $2^{\text {nd }}$ ed.), Boston: Intercultural Press.

The Hofstede Centre (2014a). What about Slovenia? Retrieved May 31, 2014, from http://geert-hofstede.com/ slovenia.html

The Hofstede Centre (2014b). What about South Korea?
Retrieved May 31, 2014, from http://geert-hofstede. com/south-korea.html.

The Levin Institute (2015). Globalization 101. Retrieved February 11, 2016, from http://www.globalization101. org/what-is-globalization/

Treven, S. (2001). Mednarodno organizacijsko vedenje. Ljubljana: GV Založba.

Završnik, B., \& Miglič, G. (2010). Pomen kulturnih razlik $\mathrm{v}$ poslovnih pogajanjih. In T. Kern et al. (Eds.), Človek in organizacija (pp. 1765 - 1772). Kranj: MO.

Matej Tušar started his work in 2008 at Kolektor Group as sales manager, immediately after graduation in organizational sciences at the University of Maribor, Faculty of Organizational Sciences Kranj. In the period January 2010 - December 2014 he was a vice president of Kolektor Sinyung Co., Ltd. Located in Gumi, South Korea, where he co-managed the company conisisting of approx. 120 people and 30 million EUR yearly turnover. In the period February 2013 - December 2014, he also successfully overtook full responsibilities as representative director of the company. With 2015, he overtook the position as key account manager in Kolektor.

Anja Žnidaršič is an Assistant Professor of Quantitative Methods at the Faculty of ganizational Sciences, University of Maribor, Slovenia. Her main research interests are social network analysis, micro-enterprises and information-communication technology, and students' performance in methodological courses.

Gozdana Miglič received her Ph.D. in sociological sciences at the Faculty of Social Sciences, University of Ljubljana. From 2009 she has been a lecturer at the Faculty of Organizational Sciences, University of Maribor. She is the author and co-author of several monographs and handbooks, numerous articles and conference papers, published in national and international journals. Her research is focused on human resource management, e. g. competencies models, recruitment, selection, training, career planning, organizational behavior. 